\title{
Finite element analysis of failure process for tubular joints in fire by using transient and steady heat transfer methods
}

\author{
Haicheng Zhao ${ }^{1,}$ a , Yongbo Shao ${ }^{2, b^{*}}$ and Dongping Yang ${ }^{3, c}$ \\ ${ }^{1}$ School of Civil Engineering, Yantai University, Yantai, China \\ ${ }^{2}$ School of Mechatronic Engineering, Southwest Petroleum University, Chengdu, China \\ ${ }^{3}$ Technology Inspection Center, China Petroleum \& Chemical Corporation, Dongying, China

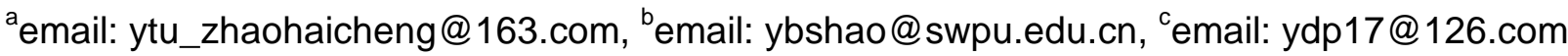

Keywords: Tubular joints; fire; steady heat transfer; transient heat transfer; finite element analysis

Abstract. Finite element model is presented by using software ABAQUS and used to carry out heat transfer analysis for tubular joints, and its reliability has been verified through comparison with reported experimental tests. Using transient and steady heat transfer theory, the critical temperatures of tubular T-joints with different geometrical parameters are analyzed. The difference of the results obtained from the two methods is discussed. The study shows that the static behavior of a tubular joint at elevated temperature is safer when transient heat transfer theory is used.

\section{Introduction}

Tubular structures are widely used in building, offshore engineering and bridge engineering etc. The design concerns for welded tubular structures focus on the static behavior, the fatigue life, the seismic performance and the fracture resistance in the past decades. In recent years, many reports on fire accident for tubular structures can be found, especially for offshore platforms. Therefore, the investigation on behavior of tubular structures at elevated temperature becomes more senseful for the safety assessment.

In a tubular structure, the connection between the tubes is called a tubular joint, which is a critical position because failure occurs here frequently. To analyze the performance of a tubular joint at elevated temperature, both finite element simulation and experimental tests have been conducted, and some useful results are obtained. Nguyen et al. ${ }^{[1-4]}$ studied the failure process of tubular T-joints at elevated temperature through experimental tests, and they also presented steady heat transfer theory to analyze the static strength of such T-joints. Chen et al. ${ }^{[5]}$ and He et al. ${ }^{[6]}$ tested the failure process of T-joints in an ISO 834 heating process, and they analyzed the static strength of the T-joints with transient heat transfer theory.

It is definitely more realistic to analyze the static strength of a tubular joint in fire by using transient heat transfer theory because such theory is based on the actual failure process. However, the analysis of a tubular joint in fire by using transient heat transfer theory is much more complicated compared to the analysis by using steady heat transfer theory. The study then aims to investigate the difference of the two methods in analyzing the failure process of tubular joints in fire.

\section{Finite element model}

Sequential thermal and mechanical analysis is used to carry out the finite element analysis for a tubular joint in fire. The following assumptions are taken: (1) effect of creep is ignored; (2) the tubular joint is heated uniformly; (3) the convective and the radiation factors are constants; and (4) T-joints are selected for analysis. The configuration of a tubular T-joint is shown in Fig. 1. Some critical positions, marked as crown, Point A (saddle) and Point B, are also shown in Fig. 1. Additionally, some normalized parameters, namely $\alpha, \beta, \gamma$ and $\tau$ are also provided. 


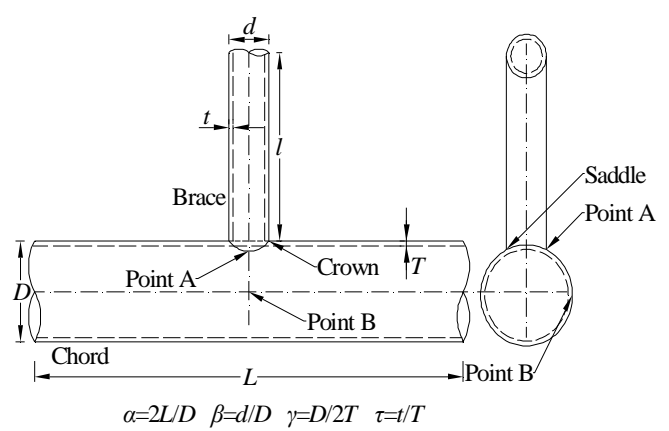

Fig. 1 Configuration of a tubular T-joint

In the meshing scheme, DC3D8 elements are used in the heat transfer analysis while C3D8I elements are used in the mechanical analysis. The element size around the brace/chord intersection is $0.01 \mathrm{~mm}$ and such size is enlarged to be $0.02 \mathrm{~mm}$ in the region far away from the intersection. Two layers of elements are meshed in the tube wall thickness. Both ends of the chord in a T-joint are hinged in the finite element analysis. In the steady heat transfer analysis, displacement at the brace end is controlled to apply axial load and the joint is kept to be in a fixed temperature. In the transient heat transfer analysis, load is applied at the brace end and the joint is then heated to failure.

The material properties of the steel are listed as follows: density: $7850 \mathrm{~kg} / \mathrm{m}^{3}$; Poisson's ratio: 0.3 ; yield stress at ambient temperature: $235 \mathrm{~N} / \mathrm{mm}^{2}$; elastic modulus: $206 \times 10^{3} \mathrm{~N} / \mathrm{mm}^{2}$. The stress-strain relation, the specific heat, the elongation and the conductivity are all referred to the specifications in $\mathrm{EC} 3^{[7]}$. The convective and the radiation factors are $25 \mathrm{~W} \cdot \mathrm{m}^{-2} \cdot \mathrm{K}^{-1}$ and 0.7 respectively. The heating process is in accordance with ISO 834 curve.

The experimental results reported by Nguyen et al. ${ }^{[1]}$ are used to verify the accuracy of the steady heat transfer method while the experimental results reported by Chen et al. ${ }^{[5]}$ are used to assess the accuracy of the the transient heat transfer method. Fig. 2 shows the comparison between the finite element and the experimental results reported by Nguyen et al. ${ }^{[1]}$, and Fig. 3 shows the comparison between the finite element and the experimental results reported by Chen et al. ${ }^{[5]}$.

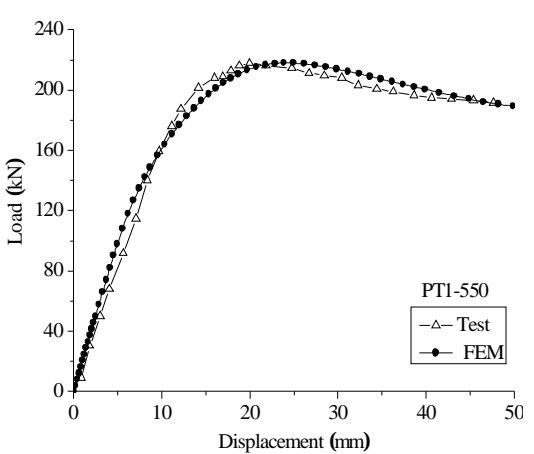

(a) specimen PT1-550

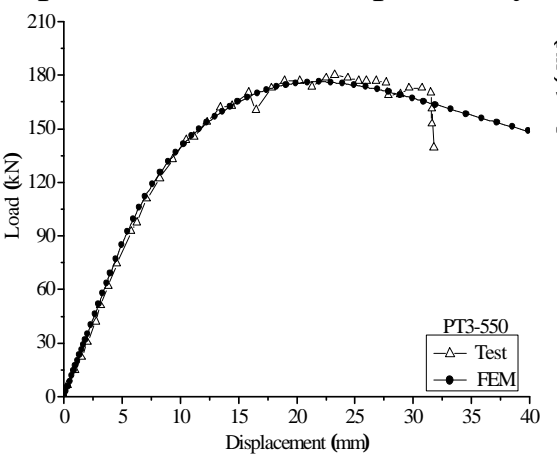

(b) PT3-550

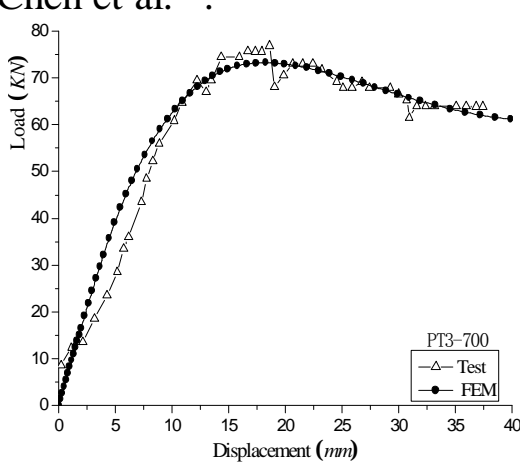

(c) PT3-700

Fig. 2 Comparison between finite element and experimental results (steady heat transfer)

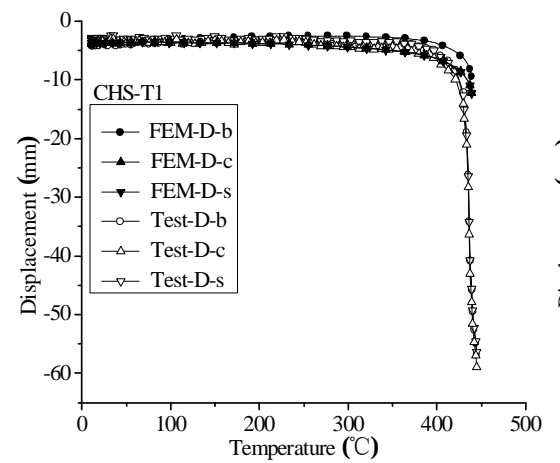

(a) CHS-T1

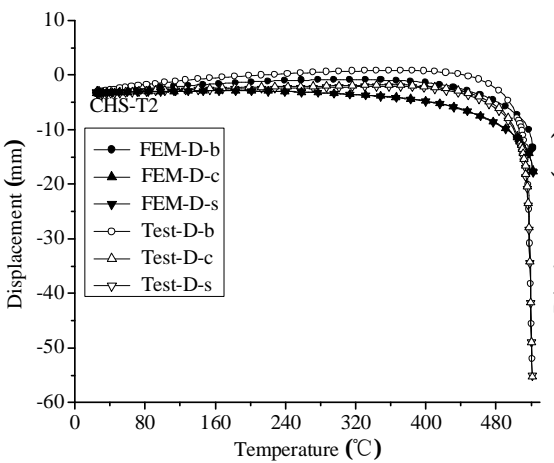

(b) CHS-T2

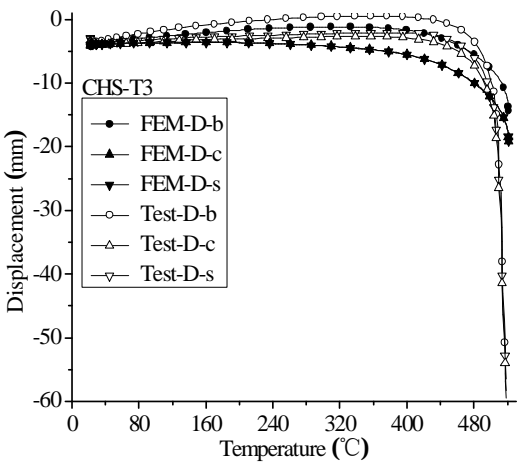

(c) CHS-T3

Fig. 3 Comparison between finite element and experimental results (transient heat transfer) 
From Figs. 2-3, it can be found that the presented finite element model can provide good estimation for the failure process of $\mathrm{T}$-joints at elevated temperature by using both steady and transient heat transfer methods. Therefore, this model is used for the following analysis.

\section{Difference of static strength obtained from steady and transient heat transfer methods}

To compare the difference of the steady and the transient heat transfer methods in predicting the static strength of a tubular joint at elevated temperature, a parametric study is conducted. The static strength of a tubular $\mathrm{T}$-joint at elevated temperature is firstly calculated from steady heat transfer method. In this method, the temperature $T_{\mathrm{s}}$ is fixed to be constant, and the T-joint is loaded till failure. From the load-deformation curve, the static strength of the T-joint can be determined, and it is denoted by $F_{\mathrm{u}}$. The deformation of the T-joint corresponding to $F_{\mathrm{u}}$ is denoted by $\delta_{\mathrm{s}}$. In the transient heat transfer method, the brace is firstly loaded with a value of $F_{\mathrm{u}}$ at ambient temperature. The load is kept constantly, and the T-joint is heated in an ISO 834 heating curve. When the deformation of the T-joint is also $\delta_{\mathrm{s}}$, the corresponding temperature $T_{\mathrm{t}}$ is defined as the critical temperature. The two temperatures can be compared to evaluate the difference of the two methods.

Five models as listed in Table 1 are analyzed by using the two methods. The chord diameter of each model is fixed to be $300 \mathrm{~mm}$, and all other dimensions can be calculated from the normalized parameters.

Table 1 Parameter values

\begin{tabular}{llllllrl}
\hline Model & $\boldsymbol{\alpha}$ & $\boldsymbol{\beta}$ & $\boldsymbol{\gamma}$ & $\boldsymbol{\tau}$ & $\mathbf{T}\left({ }^{\circ} \mathbf{C}\right)$ & $F_{\mathrm{u}}(\mathrm{kN})$ & $\delta \mathrm{s}(\mathrm{mm})$ \\
\hline FE-1 & 19 & 0.3 & 18 & 1 & 550 & 71.21 & 5.67 \\
FE-2 & 19 & 0.6 & 18 & 1 & 550 & 113.34 & 5.61 \\
FE-3 & 19 & 0.6 & 27 & 1 & 550 & 59.00 & 7.11 \\
FE-4 & 19 & 0.6 & 18 & 0.5 & 550 & 111.57 & 5.45 \\
FE-5 & 19 & 0.6 & 18 & 1 & 800 & 20.38 & 4.94 \\
\hline
\end{tabular}

The load-deformation curves of the five models in Table 1 are plotted in Fig. 4. The deformation is the displacement difference between Point A and Point B in Fig. 1. The results illustrated in Fig. 4 are obtained from steady heat transfer analysis. Similarly, the deformation-temperature curves based on the transient heat transfer analysis can be also obtained, and the results are plotted in Fig. 5.

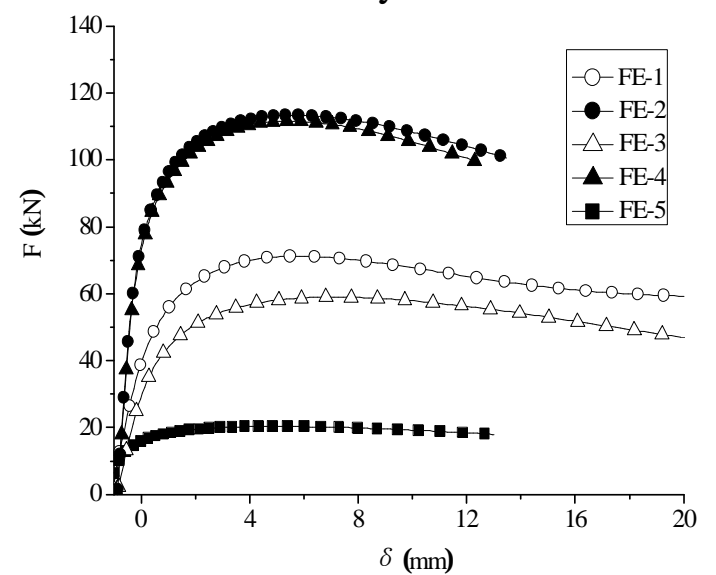

Fig. 4 Load-deformation curves

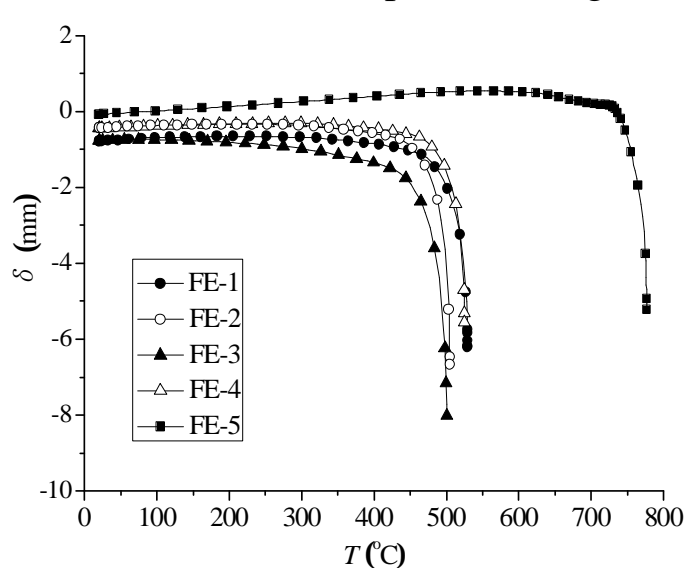

Fig. 5 Deformation-temperature curves

From the load-deformation curves in Fig. $4, F_{\mathrm{u}}$ and $\delta_{\mathrm{s}}$ are determined and they are tabulated in Table 1. Based on the critical deformation $\delta_{\mathrm{s}}$, the critical temperatures $\left(T_{\mathrm{t}}\right)$ of the five models calculated from transient heat transfer analysis, and they are tabulated in Table 2 together with the specified temperatures in the steady heat transfer analysis as listed in Table 1. From the comparison of the critical temperatures obtained from two methods, which is expressed as a ratio of $T_{\mathrm{s}} / T_{\mathrm{t}}$, it is clear that the critical temperatures obtained from the transient heat transfer analysis are lower than the 
corresponding results obtained from steady heat transfer. Such lower values indicate that the transient heat transfer method provides a safe estimation compared to the steady heat transfer method.

\begin{tabular}{llll}
\multicolumn{4}{c}{ Table 2 Values of $T_{\mathrm{s}}$ 、 $T_{\mathrm{t}}$ and $T_{\mathrm{s}} / \boldsymbol{T}_{\mathbf{t}}$} \\
\hline Model & $\left.T_{\mathrm{s}}{ }^{\circ} \mathrm{C}\right)$ & $T_{\mathrm{t}}\left({ }^{\circ} \mathrm{C}\right)$ & $T_{\mathrm{t}} / T_{\mathrm{s}}$ \\
\hline FE-1 & 550 & 529 & 0.96 \\
FE-2 & 550 & 504 & 0.92 \\
FE-3 & 550 & 500 & 0.91 \\
FE-4 & 550 & 525 & 0.95 \\
FE-5 & 800 & 778 & 0.97 \\
\hline
\end{tabular}

Table 2 also indicates that the two methods produce much close estimation for the critical temperature, and the masximum error is within $10 \%$ since the ratio of $T_{\mathrm{s}} / T_{\mathrm{t}}$ is less than 1.0 and bigger than 0.9.

\section{Conclusions}

Through finite element analyses based on two methods: steady and transient heat transfer, it is found that the two methods provide close estimation for the failure process of tubular joints in fire. However, the critical temperature calculated from transient heat transfer method seems to be lower and safer.

\section{References}

[1] M.P. Nguyen, T.C. Fung, K.H. Tan. Tubular Structures XIII, edited by B. Young, CRC Press, Hong Kong (2010). p. 725-732.

[2] M.P. Nguyen, K.H. Tan, T.C. Fung. Tubular Structures XIII, edited by B. Young, CRC Press, Hong Kong (2010). p. 733-740.

[3] M.P. Nguyen, T.C. Fung, K.H. Tan. Tubular Structures XIV, edited by L. Gardner, CRC Press, London (2012). p. 599-606.

[4] M.P. Nguyen, T.C. Fung, K.H. Tan. Tubular Structures XIV, edited by L. Gardner, CRC Press, London (2012). p. 607-614.

[5] C. Chen, Y.B. Shao, J. Yang. J. Constr. Steel Res. Vol. 85 (2013), p. 24-39.

[6] S.B. He, Y.B. Shao, H.Y. Zhang, D.P. Yang, F.L. Long. Engineering Failure Analysis Vol. 34(2013), p. 204-216.

[7] EN 1993-1-2. Eurocode 3: Design of Steel Structures-Part 1-2 General rules-Structural Fire Design (British Standards Institutions, UK 2005). 